MATEC Web of Conferences 16, 10001

(2014)

DOI: $10.1051 /$ matecconf/ 20141610001

C Owned by the authors, published by EDP Sciences, 2014

\title{
Performance based analysis of hidden beams in reinforced concrete structures
}

\author{
Samir H. Helou ${ }^{1}$, Riyad Awad ${ }^{1}$ \\ ${ }^{1}$ Civil Engineering Department, An-Najah National University, Nablus, Palestine.
}

\begin{abstract}
Local and perhaps regional vernacular reinforced concrete building construction leans heavily against designing slabs with imbedded hidden beams for flooring systems in most structures including major edifices. The practice is distinctive in both framed and in shear wall structures. Hidden beams are favoured structural elements due to their many inherent features that characterize them; they save on floor height clearance; they also save on formwork, labour and material cost. Moreover, hidden beams form an acceptable aesthetic appearance that does not hinder efficient interior space partitioning. Such beams have the added advantage of clearing the way for horizontal electromechanical ductwork. However, seismic considerations, in all likelihood, are seldom seriously addressed. The mentioned structural system of shallow beams is adopted in ribbed slabs, waffle slabs and at times with solid slabs. Ribbed slabs and waffle slabs are more prone to hidden beam inclusion due to the added effective height of the concrete section. Due to the presence of a relatively high reinforcement ratio at the joints the sections at such location tend to become less ductile with unreliable contribution to spandrel force resistance. In the following study the structural influence of hidden beams within slabs is investigated. With the primary focus on a performance based analysis of such elements within a structure. This is investigated with due attention to shear wall contribution to the overall behaviour of such structures. Numerical results point in the direction that the function of hidden beams is not as adequate as desired. Therefore it is strongly believed that they are generally superfluous and maybe eliminated altogether. Conversely, shallow beams seem to render the overall seismic capacity of the structure unreliable. Since such an argument is rarely manifested within the linear analysis domain; a pushover analysis exercise is thus mandatory for behaviour prediction under strong seismic events. In such events drop beams have the edge.
\end{abstract}

\section{Statement of the problem}

Hidden beams are quite popular and form an essential part of modern reinforced concrete framed structures. The idea caters for strict architectural preferences. They provide better height clearance and simplify internal partitioning. This is in addition to removing potential obstacles in the way of electromechanical duct works. Furthermore, it is noticed that thorough discourse about their structural efficiency is hitherto lacking. This applies to their performance under static as well as dynamic loadings; albeit modern structures are necessarily code required to be earthquake safe. The following is a numerical study targeting the capability assessment of such structural elements. The study is comparative among shallow and drop beams in medium size structures with and without shear walls.

The width of shallow beams is usually larger than the size of the supporting columns and their depth is normally equal to the depth of the rest of the slab. Moreover, it is safe to presume that such beams have a high reinforcement ratio particularly at the column connection in order to compensate for the insufficient effective depth; hence ductility is a diminished inherent feature. Since such beams are not fully supported on columns, they render the spandrel connection capacity unreliable, Furthermore, in the orthogonal direction the vulnerability is more pronounced since the beams in this direction are either narrower, so called tie beams or altogether absent. Finally, it is justifiable to make the added presumption that the overall seismic strength and the stiffness of the building are compromised thus lowering the fundamental frequencies and thus rendering the structure deficient under the action of any strong motion ground excitation. In summary the vulnerability of shallow beams is attributed to the following arguments: 
$>$ The small effective depth in comparison with conventional beam sections.

$>$ The diminishing of ductility due to the excessive reinforcement at interior supports.

$>$ The shallow section renders the beam weaker in strut compressive force resistance.

$>$ Shallow beams are normally narrower than the columns on which they connect. Therefore torsion action is amplified.

The present study intends to address numerically the behaviour of such shallow elements from the perspective of performance and behaviour. The modern approach to such an undertaking is through Performance Based Engineering widely known as the Static Inelastic Pushover Analysis. This is an effective analysis tool that predicts post yield structural behaviour; identifies failure modes and the potential for progressive collapse. Towards such intention a framed structure is selected which is comprised of conventional column and slab sections. Shallow beam elements are distributed over the various storey levels. The building configuration selected is that of simple topology that manifests the study objective. For the comparative study the building selected is analyzed as a bare frame structure then with the inclusion of judiciously distributed shear walls and finally with drop beams replacing all shallow beams.

\section{The building numerical models}

The primary intention of the present study is to numerically investigate vernacular moment resisting structures in Palestine from the perspective of performance during strong seismic events. The selected topology for the present undertaking is arbitrarily comprised of five levels i.e. $\mathrm{G}+4$ structure with each floor level having 3.50 meter height. The structure, shown in Figures 1 and 2, has 2 equal spans in one direction and 3 spans in the orthogonal direction. The span lengths are all equal; they are of 7 meters length in one direction and 6 meters in the other. The building is acted upon by equally distributed Live Load of $4.0 \mathrm{KN}$ per square meter in addition to a Dead Load of 3.0 KN per square meter. The numerical models are constructed using SAP 2000. The slab thickness in all models is set to $20 \mathrm{~cm}$. The periphery ledger beams have a $30 \times 80 \mathrm{~cm}$ cross section while the hidden beams have a $25 \times 80 \mathrm{~cm}$ cross section. All columns are square of $50 \times 50 \mathrm{~cm}$ sections.

In one building there are no shear walls; it is a bare frame. In the second study model there are judiciously distributed shear walls of $20 \mathrm{~cm}$ thickness in order to simulate real vernacular structures. The symmetric arrangement is intended to exclude torsion modes. Supports conditions are assumed rigid. Reinforcement placement and details follow the local customary practices. For comparison purposes the same structure but with its drop beams replaced by shallow ones is designed and analyzed under exactly similar conditions.

\subsection{Material properties:}

The standard construction materials used in the local reinforced concrete construction industry include concrete of $\mathrm{f}^{\prime} \mathrm{c}=30 \mathrm{MPa}$ with a Modulus of Elasticity equal to $22,360 \mathrm{MPa}$ and the reinforcing steel bars commonly used have a yield stress Fy = $410 \mathrm{MPa}$ and a Modulus of Elasticity of 200,000 $\mathrm{MPa}$.

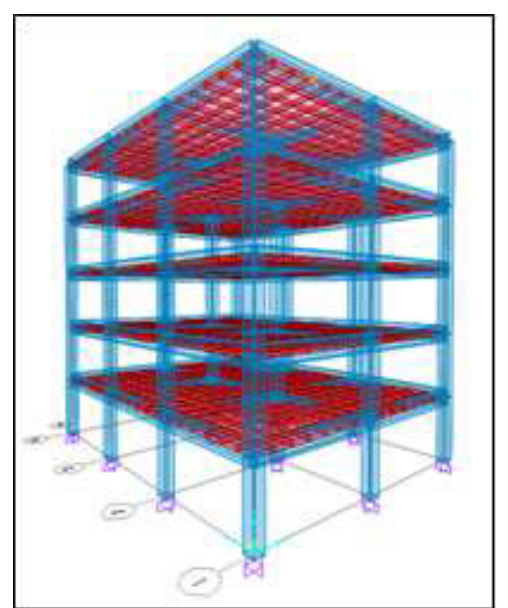

Figure 1. An Isometric View of the Study Model

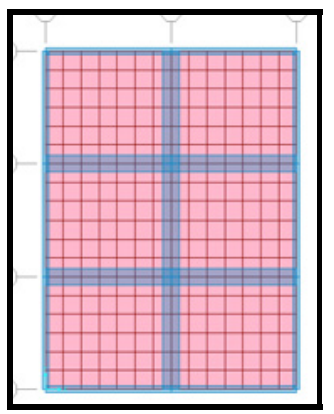

Figure 1. Plan of the Study Model

\subsection{Pushover analysis:}

The structures selected are properly analyzed and designed for static and seismic loads using the Response Spectrum Method and adequate code specified load combinations. Moreover, in order to further explore the behaviour of shallow beams under strong seismic events a three dimensional Pushover Analysis as per FEMA 356 and ATC-40 is conducted. This is because response characteristics 
cannot be thoroughly investigated using standard linear methods of analysis. Pushover analysis has gained considerable popularity over the recent few years particularly because linear analysis methods are code descriptive suitable only for low intensity loads; such an analysis route becomes irrelevant in a strong seismic event. In pushover analysis, which is a simplified nonlinear technique, the structure is subjected to monotonically increasing lateral forces until a target displacement is reached. In the present case a $60 \mathrm{~cm}$ target control displacement at the top floor is set in order to scrutinize potentially brittle elements. For the present discourse the focus is on the beam-column connections and on the axial force demand of the supporting columns. As such, performance based seismic engineering is combined with seismic hazard assessment in order to compute seismic performance. The analysis is conducted after Fema plastic moment hinges are defined at the locations where the large reinforcement ratio at such localities would render the shallow beams as brittle. This is prescribed at 5\% of the member length away from the respective neighbouring joint. This is applied on all beams as well as on all columns. However, Fema hinges are distinctively different than column hinges. The pushover analysis is performed in the $\mathrm{X}$ - direction as well as in the Y-direction yet with the same magnitude of targeted displacement.

The same procedure is followed after introducing shear walls, modelled as shells, symmetrically placed at the facades of the building; in a third model drop beams replace all hidden beams. This covers the investigative purpose of the present study. This is accomplished by comparing the capacity and demand curves of the various building scenarios as well as the respective hinge deformation; the comparative study is thus conducted. The seismic coefficient factors are set to $\mathrm{Ca}=0.2$ and $\mathrm{Cv}=0.2$ for all cases.

made. The floor slabs are defined as rigid flat plates. The performance point in the X-direction is (Teff, Beff $)=(0.458,0.110)$ and in the $Y$-direction is $(0.459,0.089)$. It is readily noticed that the structure manifests better capacity due to the presence of shear walls. This is illustrated in Figure 8 and in Figure 9. The shear walls are modelled as layered elements made of unconfined concrete while invoking the nonlinear behaviour of the reinforcement bars. The effects of sectional cracking effects are not included.

Case I: Bare Frame Results: The performance point is defined as the intersection of the capacity of the structure with the demand curve of the earthquake. The performance point in this case and in the $\mathrm{X}$ direction happens at (Teff, Beff) $=(1.808,0.222)$; whereas in the $\mathrm{Y}$ direction the performance point is at
(1.405, 0.108). Note the evident Collapse Prevention marker in the shorter direction. These results are in shown in Figure 3 through Figure 6 [step 5 in hinge results].

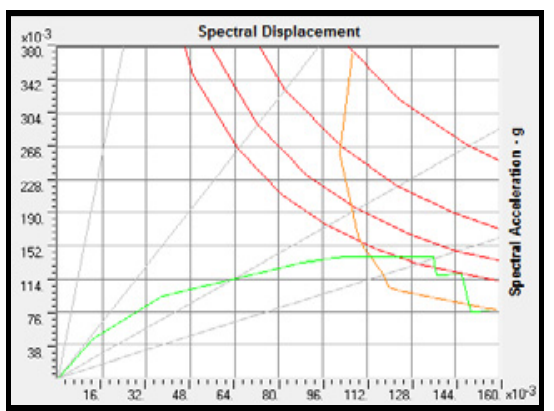

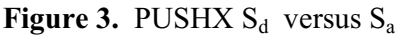

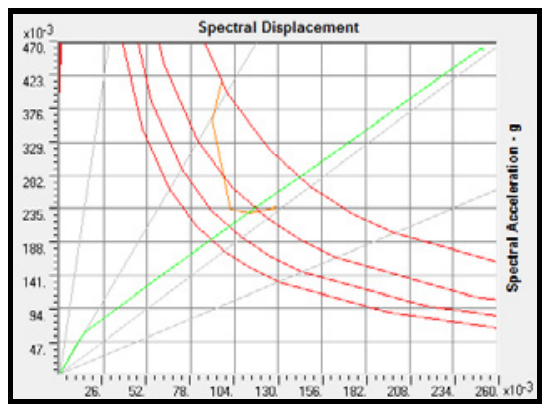

Figure 4. PUSHY $S_{d}$ versus $S_{a}$

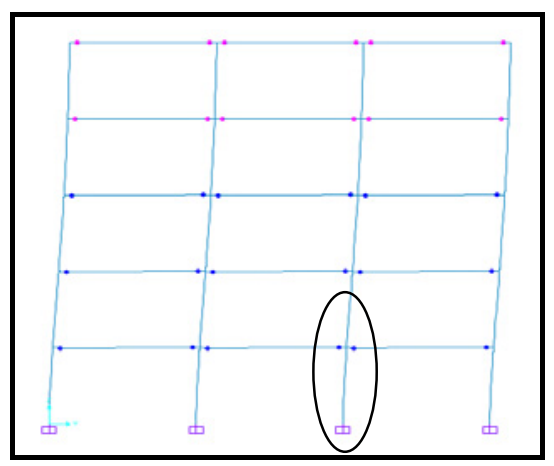

Figure 5. Deformed Shape of Bare Frame in the Y X Directions

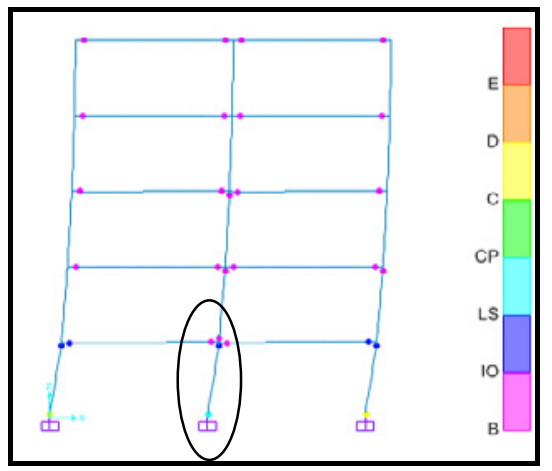

Figure 6. Deformed Shapes of Bare Frame in the X Directions 


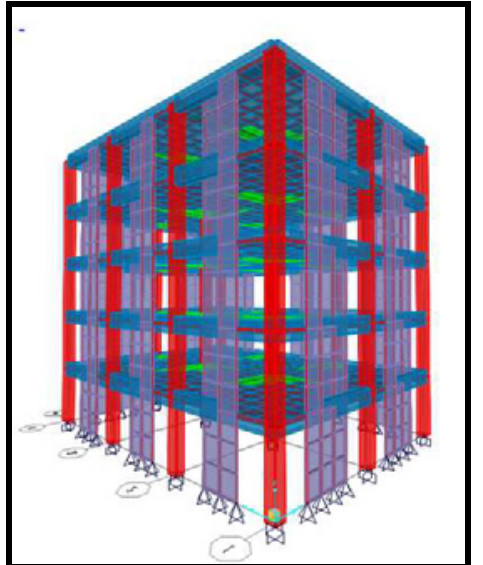

Figure 7. Isometric View of the Model with Shear Walls

Case II: In this case the shear walls are defined as non linear shell elements in flexure shown in Figure 7. They are introduced symmetrically around the periphery of the building. The walls are $20 \mathrm{~cm}$ thick and about 2 meter wide in order to account for possible window openings. Wall meshing is properly

Case III: Bare frame structure in which drop beams replaced all hidden beams in the structure. The results of this case indicate a performance point (Teff, Beff) $=(1.752,0.259)$. The results are shown in Figure 10 and in Figure 11.

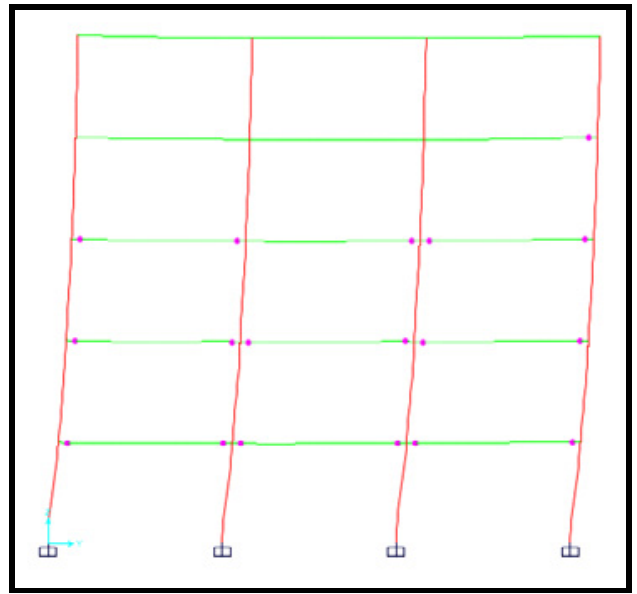

Figure 8. PUSHX hinge results

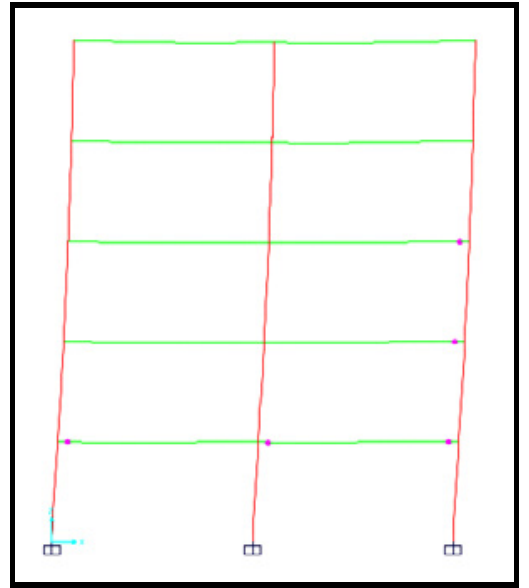

Figure 9. PUSHY hinge results

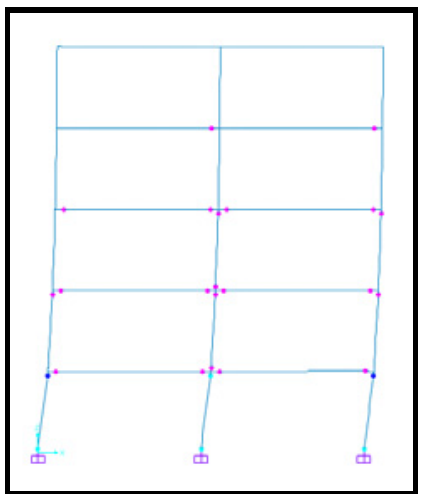

Figure 10. Deformation PUSHY

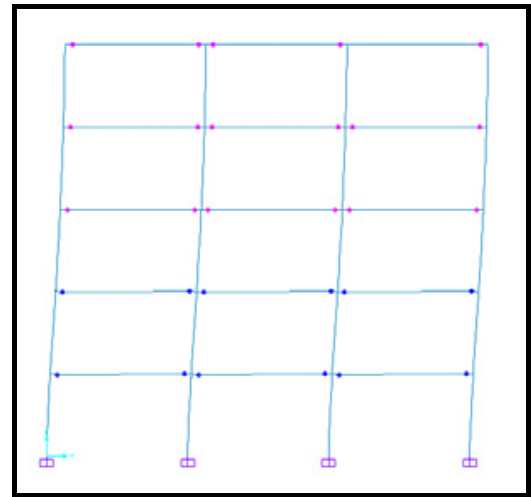

Figure 11. Deformation PUSHX 


\section{Cconclusion}

Based on the numerical exercise performed on the different structural systems that include shallow beams within the roofing system, it is concluded that shallow beams are potentially vulnerable to collapse in strong motion seismic events. The foregoing results indicate that the selection of shallow beam elements within a structural system is a judicious choice that requires a thorough in-depth analysis within the context of the overall structural behavior.

Linear analysis is illusive and could be misleading as it may lead to erroneous results. The present study indicates that the use of shallow beams demands focused attention, proper in depth analysis and meticulous detailing in order to avoid high reinforcement ratios at the beam end and column junctions. Furthermore, it is concluded that the behaviour of hidden beams is governed by an overall structural response rather than being a localized behaviour. In shear wall building shallow beams seem to be better protected than they are in bare frame structural construction. This is attributed to the fact that bare frame structures have reduced lateral load capacities compared to frames with shear infill walls as manifested by the respective performance point values. Furthermore, in the weak direction i.e. in the direction of fewer bays the phenomena is more pronounced. It is of interest to note that since the columns supporting hidden beams tend to be significantly stiffer in such structures they approach Collapse Prevention stage a lot sooner. Therefore it can be safely stated that hidden beams add to the vulnerability of the supporting columns particularly at lower levels; hence their presence contradicts the underlying concept of strong column-weak beam preferred arrangement.

It is to be noted that the building with drop beams manifests a more robust structural behaviour in comparison with the one with shallow beams; this is based on Performance Based Analysis discourse. To circumvent such an outcome it is recommended that shallow beams, if and when desired, are to be detailed in such a manner that their ends would not lend themselves for potential hinge formation due to excessive steel reinforcement.

\section{References}

1. ACI 318-08, Building Code Requirements for Structural Concrete and Commentary, American Concrete Institute (2008).

2. E.P, Popov, E, Cohen, K., Koso-Thomas, K., Kasai, ACI Structural Journal, 89 (6). 607-16 (1992).

3. Dominguez, D., Lopez-Almansa, F., BenaventCliment, A., Engineering Structures, 46, 687-702 (2013). 